\title{
Analysis on Cultural Industry Development Strategy of Jingchu Cultural Circle Based on Growth Pole Theory
}

\author{
Chun-Yan LI, Yuan SUN* \\ School Of Marxism, Hubei University of traditional Chinese Medicine \\ 156738577@qq.com \\ *Corresponding author: Yuan SUN \\ Hubei University of traditional Chinese Medicine
}

Keywords: Jingchu cultural circle, Growth pole of cultural industry, Development strategy.

\begin{abstract}
During the process of Jingchu culture construction, Hubei Province focuses on building growth pole of cultural industry in Wuhan urban circle and that of eco-cultural industry in western Hubei, forming two-pole development strategy for Jingchu cultural circle. Regional culture orientation by pursuing dislocation development will be conducive to giving full advantages of two growth poles of cultural industry. In system construction, it is required to establish the policy system of classification management and reasonable financial supporting system, and exert the government's macro-regulating functions in a bid to develop Jingchu cultural circle into a regional culture brand with developing vitalities and competitive advantages.
\end{abstract}

\section{Introduction}

The theory cultural circle was first put forward by scholar Fritz Graebner (Germany) and $\mathrm{W} \cdot$ Sehmidt (Austria) at the beginning of last century. It regards that there are several cultural circles in the world and each encompasses a certain common parts of material and spiritual culture. Cultural circle is made up of core (origin of culture) and periphery (area of culture acceptance), core part affects and restricts periphery, while the latter reacts upon the former. With the passage of historical conditions, both can be alternative.[1] As Jingchu culture has already formed relatively stable and distinctive cultural circle, to construct more attractive and competitive Jingchu cultural circle with distinguishing characteristics is an important task for Hubei CPC party provincial committee and government in cultural construction to perform. The article is intended to analyze the development strategy of Jingchu culture by using cultural circle theory in sociology and growth pole theory in economics and provide certain references for the construction of Jingchu culture. Two-core strategy: top-level design of cultural industry growth pole in Jingchu cultural circle

The strategic objective of culture-rich province can be realized possibly through overall planning. By viewing the achievements of Jingchu culture construction in recent years, it is not hard to find that Wuhan is the flagship in Jingchu area depending on its position of cultural, educational, scientific and economic centre. This feature determines the cultural strength of Jingchu cultural circle basically manifests a "Single Core" pattern and regards Wuhan City as the core for distributing culture, science and education resources primarily, showing a characteristic of "concentric circle and annular band"[2]. Provided that Wuhan is emphasized excessively as a growth pole of culture industry, its radiant ability is not going to make western remote and border areas involved, which easily causes "islanding effect" for growth pole. The strategy of building eco-cultural tourism industry in western Hubei can overcome the defect exactly. In Nov 2008, the CPC party provincial committee and government of Hubei decided to concentrate the efforts to build "Wuhan urban circle" and "urban agglomeration in the middle-lower reaches of the Changjiang River", and hopes the construction of eco-cultural tourism industry in western Hubei will bring new opportunities for further development of Hubei cultural industry.

In view of this, we believe the construction of Jingchu cultural circle should actively promote development of two growth poles of cultural industry and follow the ideas of "one circle and two poles, linking points with line, driving area with line and highlighting the points". First, under the 
construction of Jingchu cultural circle, pay attention to synergetic development of the entire cultural circle and divide it into two growth poles of cultural area, namely cultural industry of Wuhan urban circle and eco-cultural industry of western Hubei. Second, the growth pole can't show a state of fragmentation, but axis such as cultural concept, public transportation, economic technology and common interests should be used to connect cultural factors, two growth poles of Wuhan urban circle and eco-cultural industry of western Hubei requires to be highlighted and their successful experiences are applied to promote cultural industries of other areas, the construction of Jingchu cultural circle targets network structure. Why two growth poles of cultural industry are established is to prevent polarization phenomenon [3]. The core and periphery act upon each other according to cultural circle theory. Therefore, one growth pole of cultural industry in Jingchu cultural circle is inseparable from the other, both are organically related as a whole. Through giving full play to key roles, two growth poles will mobilize cultural interaction between peripheral and core areas and boost the vitality of cultural development of Jingchu cultural circle.

The key issue of building Jingchu cultural circle is how to deal with two growth poles in a good way. First, take full advantage of the government's coordination function, establish cooperation and communications between two poles and integrate cultural resources to realize resource sharing and cultural interaction; carry out integrated management including free flow of information, talents and capital within the area, and coordination of supervising culture development process, maintaining the power credit of market entity, etc. second, under the condition of cultural industrialization, actively guide and support enterprises and capital from different industries and areas into two growth poles of cultural industry participating in the integration, reorganization and reconstruction of cultural enterprises, foster a batch of competitive and influential culture industry group which can connect two growth poles, and guide cultural industry inside the circle to develop towards internationalization, industry mercerization and product branding. Third, establish game mechanism through which both growth poles can either compete or cooperate. Two growth poles of Jingchu cultural circle should develop cooperation in cultural resources such as regional traffic condition, science and technology, platform for cultural industry development and cultural investment to truly realize mutual communication of information, recognition of qualification, sharing of knowledge and mobility of labor, as well as economic linkage and benefit sharing of both.

\section{Dislocation Development: Orientation of Differences between Cultural Industry Growth Poles in Jingchu Cultural Circle}

Regional culture dislocation refers to distinctive natural sceneries, humanistic characteristics, cultural industries, images, functions and customs in different areas shaped by geographical and historical factors. The purpose of dislocation development of regional culture is to manifest distinctive and superior culture brands in different areas after various cultural resources flow and cluster again. Differentiation positioning will help achieve different division based on distinctive features and regional mobility of non-homogeneous factors, however, the gathering of similar cultural factors in a certain region can realize optimal allocation of cultural resources, gradually promote the development of culture in characteristics and differentiation, establish comparative advantage and make regional culture have its competitive capacity with unique feature.

Cultural characteristics are the theme of regional culture development. "Cultural wisdom and value concept in different parts of the world enrich human society, the basic point when we consider such issue is to integrate and promote different cultures by combining real situation of our country and region, and find a beautiful future for mankind"'[4]. During the construction of Jingchu cultural circle, it is required to focus on maintaining cultural characteristics and carry out the principle of dislocation development. First, Jingchu culture should be in dislocation development with other domestic cultures, highlighting its characteristics and shaping unique cultural brand and image, for instance, Beijing's international cultural exchange, Shanghai's international financial culture, Guangzhou's trade culture, as well as Shenzhen's creative and fashionable culture. Cultural orientation for each city can reflect certain differences.

From a view of broader area coverage, eastern regions are suitable for developing technology and 
fund-intensive cultural industries, western regions fit those involved in ethnic culture and natural resources, but cultural industries with traditional and modern tech characteristics are more appropriate for middle regions. With rich historical cultural connotations, Jingchu cultural circle integrates profound traditional culture and modern technology organically, owning large prospect and advantages of dislocation development. Second, central cities or cultural patterns within Jingchu region should remain characteristics of their own as much as possible and avoid cultural convergence phenomena. In contrast, Wuhan is more powerful in such cultural industries as exhibition, cartoon, printing, news publishing and performing arts. the eco-cultural industry growth pole in western Hubei features in abundant ecological resources, deep cultural deposits and culture tour having taken shape. Cultures in other areas also need to highlight distinctive characteristics to realize dislocation development in addition, folk culture in Jingchu region such as Yan Emperor Shen Nong, Three Kingdoms, ancient architectural complex in Wudang Mountain, Ming xian Tomb of Mingxiang, Pan long City in Wuhan and Leigudun Burials in Suizhou enrich cultural connotations of each area and make differential positioning of Jingchu cultural circle have more choice factors. Third, existing distinctive cultures also need to be innovative continuously and even realize the differentiation with itself from the vertical where appropriate. Distinctive cultures can't stick to convention for remaining prosperous, but adopt new technology and concept and innovate methods of cultural communication. It is required to go beyond themselves on the basis of original culture and keep the vitality of regional culture.

Through dislocation development and depending on Internet, transportation and postal communication as the passage, play radiation and driving role of growth pole of cultural industry in Wuhan urban circle and eco-cultural growth pole in western Hubei on middle and small-sized cultural areas, form apparent agglomeration effect between middle and small-sized cultural areas and two growth poles, and establish complicated network system interacting on each other within the entire Jingchu cultural circle. In this system, different layers of cultural areas can select characteristic culture industry of their own according to the principle of relative advantages, effectively avoid convergence phenomena and realize the goal of "appreciate the culture/values of others as do to one's own and make the world harmonious”.

\section{System Construction: Supporting System of Cultural Industry Growth Poles in Jingchu Cultural Circle}

Fostering the growth pole of culture industry in Jingchu cultural circle needs the help of supporting measures such as policies and regulations, finance, government's macro-control and supervision for the sake of resources integration and improvement of cultural development results. Government policy guidance will play a key role in whether Jingchu cultural circle can make planned achievements in its development. To build Jingchu cultural circle well, there should be certain creativity in policy systems. Policies will be established specific to different cultural factor attributes of Jingchu cultural circle.

In particular, the following aspects can be considered: first, improve pertinence of cultural system according to different types of cultural industry designs and systems. Divide Jingchu culture into public and operation one. Take a full consideration to differences between two kinds of cultures in policy making. Therefore, it is required to consciously divide cultural policies into public cultural policy and operation culture one. The main objective of the former is to play the role of culture in social welfare, while the later aims to promote economic functions of culture. Currently, there have been complete policy systems for public culture in Jingchu cultural circle, and what needs to be improved is to establish incentive mechanism and policy for public culture development in Jingchu cultural circle, and recognize social benefits and development vitality of public culture services, motivation and initiative of cultural workers in public culture as important consideration factors. At present, Jingchu cultural circle is urgently enhanced in policy systems of operation culture, including how to promote synergetic development of Jingchu cultural circle, cultural industry organization reform policy, regulation of cultural industry and relevant products, supervision of competitive orders and monopolistic conducts in cultural enterprises, all of which need new 
guidance in policy. In addition, pay attention to coordinate the relationship between public and operation culture policies when they are made. Second, give full play to functions of public finance and establish stable finance budget safeguard mechanism, which should provide financial support not only for construction of growth pole of cultural industry, but areas out of growth pole to show the difference and balance of regional cultural development. Distribute financial resources rationally and inspire innovative force of operational cultural entity to enhance vitality in building Jingchu cultural circle. Expand international influence and competitiveness of Jingchu culture and carry out "going out" strategy to strengthen ties of Jingchu cultural enterprises and overseas ones. Third, relevant functional department of government should perform their duties to ensure the implementation of management and coordination of competitive orders in cultural industry, reduce and root out disorders of competition and provide government's supervision and security for sound cycle development of cultural industry. In a word, undertaking various measures simultaneously is crucial for Jingchu cultural industry to gain expected effects in growth pole construction.

\section{Acknowledgement}

Fund program: the article the phased research result of training program for young and middle-aged Marxist theoreticians from Hubei colleges and universities in 2016 (Program number 16ZD066).

\section{References}

[1] Feng Tianyu. Discussion on the Cultural Cycle of Chinese Characters [J]. Forum on Chinese Culture, 2003, (2): 50-54.

[2] Ernest W. Burgdss, scholar of Chicago school of traditional human location theory, proposed urban model of concentric circle and annular band, assuming if central business district was located in central position of a city, farther peripheral area would be annular transition belt shaped by decline of urban area. See: Wang Ying. Urban Sociology [M]. Shanghai: Sanlian Bookstore, 2005, 68.

[3] Polarization phenomenon of growth pole refers that enormous attraction and centripetal force from growth pole make factors such as labor, capital and technology in surrounding areas transferred to core district, depriving the opportunity of surrounding areas to develop and enlarging the gap of economic development between them. This is the negative effect of growth pole on surrounding areas.

[4] Wu Liangyong. UIA Beijing Declaration——Future of Architecture [M]. Beijing: Tsinghua University Press, 2002. 236. 